\title{
Roles of Information and Communication Technology in Crisis Management; Case Study Security Sector Institutions in Yemen
}

\author{
Fuad Mohsen Mohammed ${ }^{1}$ Nasr and Tang Zhen ${ }^{2}$ \\ College of business administrations, Hohai University, Nanjing, China \\ ${ }^{1}$ Email address: fuadchina@yahoo.com, ${ }^{2}$ E-mail: tangzh@hhu.edu.cn
}

\begin{abstract}
This study examines and assesses the effectiveness of ICTs in the security sector institutions (SSI) in Yemen during the ongoing war and humanitarian crises. The study provides recommendation towards optimal use of IT infrastructure during crises situation by examining the role of computing information system's role in Yemen. It, also, identifies obstacles that can hinder the use of IT and gives recommendations for optimal use of IT in security apparatus. Four Institutions which have a prominent role in dealing with disasters were selected for the study and a questionnaire was designed to identify the status of ICT use in Yemen during the crises. A total of 174 questionnaires were distributed among the employees of the four institutions out of which143 (82\%) usable responses were received. The results revealed that the use of ICT in SSI is limited, and SSI mainly depends on managers' experience to deal with crises rather than appropriate application or adaptation of ICTs policy and a proactive strategy.
\end{abstract}

Keywords: ICT, crisis management, security sector institutions (SSI), yemen

\section{Introduction}

A crisis is defined as the social changes which changes the characteristics of a society [1]. The management of modern crises is a complex and multi-disciplinary process that requires the participation of many actors beyond just the emergency services. Being multi-disciplinary and multiplayer phenomena, crises management requires ideal planning, effective coordination and implementation of measures. Through careful planning and execution, one can not only reduce the impact of a crises but it is expected that through developing such best practices can enhance the overall crises management discipline by imparting the knowledge gained [2]. Furthermore, the concept of crisis management and ICT requires a thorough understanding of the socio-technical systems that could enhance crises risk management [3]. The need for coordination also raises significant public governance challenges, as crisis management functions are often exercised at sub-national levels, but most of planning and coordination takes place at the central government level. The face makes coordination capacity of crisis management a fundamental element of good governance. This also tests governments' capacity to provide the appropriate responses at the right time, in order to protect their citizens and mitigate the impact of disasters, thus ensuring that the national authorities have the right tools and institutional framework for coordinated action [4].

Since the end of the last century, technology has become a widespread phenomenon in most developed and developing countries. But, the Arab world generally and the Republic of Yemen specifically in the last decade has witnessed a rapid and comprehensive revolution in IT. However, many researchers reported that most of the Middle East and North African (MENA) countries, i.e., Arab countries, including Yemen need to promote their ICT policies and improve using of new ICTs [5]. In Yemen, computers have been made available in the most of the government institutions, but their use is very limited. In order to more fully participate in the information age and to keep up with the 
technological advances of more developed countries, these countries must be ready to adopt a more comprehensive attitude towards ICT. Government of these countries must be ready for adopting proper policies and formulating strategies which are essential for mobilizing all stakeholders and disseminating the opportunities created by the information society, planning, designing and implementing e-government programs [6].

Recently, an increasing number of institutions, organizations from both governmental and non-governmental sector and particularly. The security sector in Yemen has experienced various hazards [7-8]. Currently, the security situation in Yemen is suffering more challenges, so the government should investigate the failure of the country's security agencies, especially the inability of the security agencies which confronting disasters and crises for reducing the repeated security crises [9]. Hence there should be a complete repair of the security services to abort these security crises. ICT knowledge processes and systems are essential in handling the various security challenges in all Yemen.

The current system assessment in ahead of time and before the outbreak of the crisis, it represents one of the main challenges of [10]. In the security sector in Yemen, there has been significant change in the perception of challenges in the field of crisis management. Against this backdrop, this paper seeks firstly to shed insight on the role that ICTs play as a response to crises and disaster management in the operations rooms of SSI. Then, we propose some recommendations for leveraging available ICTs to this critical function of crisis management. An obvious one is a need for the Yemeni government to partner with ICTs firms to increase the available technology infrastructure and advance the nation's telecommunication sector.

This study is designed to explore how Yemeni SSI deal with crises and disasters and what is the extent of using ICT in crisis management. The prime focus was to obtain preliminary insights and test theory. The rest of the paper is organized as follows: first, the research model is presented, followed by the research methodology, and then extended discussion of the main findings was made. Lastly, the conclusions, recommendations and the directions of future research are presented.

\subsection{Research questions and hypotheses}

This study explores the answers to the following research questions:

RO1: What reality and the efficiency of ICTs commonly used in response to crises and disasters in the SSI in Yemen?

RO2: What are the obstacles and solutions to use of ICT in crisis management?

Based on the answers to above mentioned questions, the hypotheses are designed as follows.

H1: No relationship (effect) is statistically significant at (0.05) level between the efficiency of IT and variable of SSI.

H2: No relationship (effect) is statistically significant at (0.05) level between the factors that hinder the use of IT and variable of SSI.

H3: No relationship (effect) is statistically significant at the (0.05) level between the solutions that proposed to avoid obstacles to the use of ICT and variable of SSI. 


\subsection{Research Model}

In this study, the SSIs (police, civil defense, surveillance and control, police hospitals) in Sana'a City (capital of Yemen) were considered. These sectors represent the first line of defense in the face of crises and disasters as shown in Figure 1. The study population consists of the staff in operations rooms of these sectors. Also, the study focused on the potential use of IT and its efficiency in crisis management through identifying the capabilities of the technology used (computers, networking, software and database) and the extent of their effectiveness through material and human resources as well as the administrative policies regarding use of ICT. Also, to examine the factors that hinder the efficient use of IT in SSI and the measurements applied to avoid obstacles and understand the impact of demographic factors on the effectiveness of using ICT.

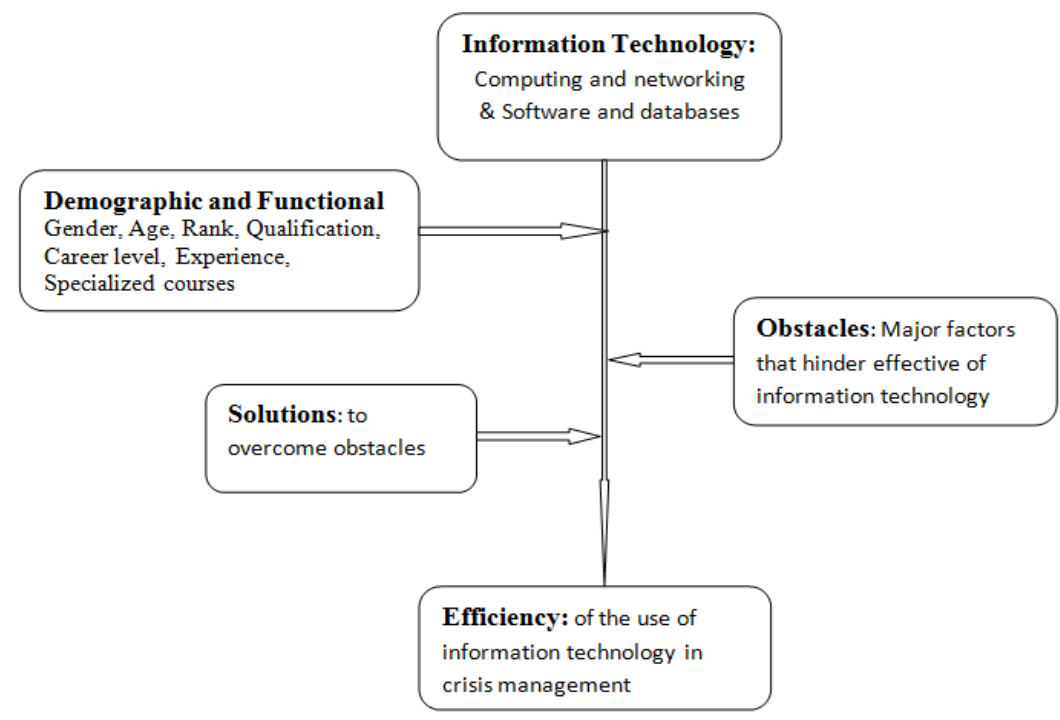

Figure 1. The Research Conceptual Model

\section{Methodology}

As shown in Table 1, a total of 143 usable responses were received against a total distribution of 174 questionnaires. . To evaluate and use the ICT systems scientific researches, direct questions were carried out through the well-designed questionnaire based on comprehensive researches done by many researchers such as David M\& Harry $\mathrm{B}, 2008$. The questionnaire was divided into five sections (i.e., $\mathrm{A}, \mathrm{B}, \mathrm{C}, \mathrm{D}$, and $\mathrm{E}$ ) with a total of 59 questions. The questionnaire in section $\mathrm{A}$ focused on demographic details of the respondents. Section B addresses the potential use of ICT (tools and equipment used daily for the purpose of running offices, storage, retrieval and extraction of reports, human resource information and databases). Section $\mathrm{C}$ was designed to assess the role of IT efficiency in crisis management (including material resources, human resources and followed administrative procedures). Section $\mathrm{D}$ investigates the major factors that hinder effective use of IT in confronting crises. And, Section E proposes the solutions which overcome obstacles of using IT in the time of crises. The questionnaire was designed based on the (Likert Scale) using Five-point rating to collect the responses of the study population. In which, point 1 represents 'strongly disagree'; 'point 2' represents 'disagree'; 'point 3' represents 'neutral'; 'point 4' represents 'agree' and 'point 5' is 'strongly agree'. These five-point rating scales were distributed to represent a balanced range between the extremely positive (point 5) and the extremely negative (point 1), and based on the responses of the study population the tendency will be determined [11], [12]. These data 
was collected in 2015. The questionnaire variables were processed in accordance with the literature. Most of the survey items were based on the researches conducted by [13], [14], although some were developed from a previous qualitative study and worked in line with other items in concept. The designed questionnaire was checked and approved by academics to ensure that our questionnaire is strongly built. Accordingly, some suggested items were added to improve the questionnaire structure.

A stratified random sample method was used to select the study samples. 174 questionnaires have been distributed to the study population, which includes the operations room's staff in the security services (i.e., Police - Civil Defense - Police Hospitals - Censorship and Control). It was done under the supervision of the senior management of the institutions and in collaboration with the relevant departments of offices. It has been recovered 143 questionnaires.

Table 1. The Distribution of Respondents to Institutions

\begin{tabular}{|c|c|c|c|}
\hline & & Frequency & Percent \\
\hline \multirow{3}{*}{ Gender } & Male & 134 & 93.7 \\
\hline & Female & 9 & 6.3 \\
\hline & Total & 143 & 100 \\
\hline \multirow[t]{5}{*}{ Institutions } & Police & 35 & 24.5 \\
\hline & Police Hospitals & 31 & 21.7 \\
\hline & Civil defense & 39 & 27.3 \\
\hline & Command and Control & 38 & 26.6 \\
\hline & Total & 143 & 100 \\
\hline \multirow[t]{5}{*}{ Age } & $30 \geq$ & 64 & 44.8 \\
\hline & $31-40$ & 59 & 41.3 \\
\hline & $40-50$ & 18 & 12.6 \\
\hline & $50 \leq$ & 2 & 1.4 \\
\hline & Total & 143 & 100 \\
\hline \multirow[t]{5}{*}{ Qualification } & High School or less & 22 & 15.4 \\
\hline & Diploma & 21 & 14.7 \\
\hline & Bachelor & 82 & 57.3 \\
\hline & Postgraduate & 18 & 12.6 \\
\hline & Total & 143 & 100 \\
\hline \multirow[t]{6}{*}{ Career Level } & less than Head of Section & 51 & 35.7 \\
\hline & Head of Section & 37 & 25.9 \\
\hline & Management Director & 26 & 18.2 \\
\hline & General manager & 1 & 0.7 \\
\hline & Other & 28 & 19.6 \\
\hline & Total & 143 & 100 \\
\hline \multirow[t]{5}{*}{ Experience } & $1-5$ years & 40 & 28 \\
\hline & 6-10 years & 27 & 18.9 \\
\hline & 11-15 years old & 33 & 23.1 \\
\hline & More than 15 & 43 & 30.1 \\
\hline & Total & 143 & 100 \\
\hline Courses of Crisis & None & 90 & 62.9 \\
\hline
\end{tabular}




\begin{tabular}{|c|c|c|c|}
\hline \multirow[t]{4}{*}{ Management } & $1-3$ courses & 41 & 28.7 \\
\hline & 4-6 courses & 11 & 7.7 \\
\hline & More than 7 & 1 & 0.7 \\
\hline & Total & 143 & 100 \\
\hline \multirow{5}{*}{$\begin{array}{l}\text { Courses } \\
\text { Information } \\
\text { Technology }\end{array}$} & None & 47 & 32.9 \\
\hline & $1-3$ courses & 49 & 34.3 \\
\hline & 4-6 courses & 37 & 25.9 \\
\hline & More than 7 & 10 & 7 \\
\hline & Total & 143 & 100 \\
\hline \multirow{3}{*}{$\begin{array}{l}\text { Forums in Crisis } \\
\text { Management }\end{array}$} & Yes & 55 & 38.5 \\
\hline & No & 88 & 61.5 \\
\hline & Total & 143 & 100 \\
\hline \multirow{3}{*}{$\begin{array}{l}\text { Forums } \\
\text { Information } \\
\text { Technology }\end{array}$} & Yes & 47 & 32.9 \\
\hline & No & 96 & 67.1 \\
\hline & Total & 143 & 100 \\
\hline \multirow{4}{*}{$\begin{array}{l}\text { System } \\
\text { Department }\end{array}$} & Manual system & 28 & 19.6 \\
\hline & $\begin{array}{l}\text { System depends on the } \\
\text { computer }\end{array}$ & 16 & 11.2 \\
\hline & $\begin{array}{ll}\text { Manual system and } \\
\text { computer together }\end{array}$ & 99 & 69.2 \\
\hline & Total & 143 & 100 \\
\hline
\end{tabular}

The data were collected, analyzed and presented in the table's form, study questions and three hypotheses were stated, and the responses to the objectives were discussed. Then, the analysis related to the research hypothesis was conducted using Statistical Package for the Social Sciences (SPSS) software.

\section{Results}

\subsection{The Reality of the Use of Computers and Networks}

In this part, we have investigated the potential of available IT in the SSI that used in security crisis management. This part refers to the all means and tools that are used in various ICT. The questions refer to tools and equipment which are used on a daily basis to run the offices, purposes of storage, retrieval and extraction of reports, human resource information and databases. Table 2 shows the details of thirteen questions associated with the potential use of IT, including the answers of the respondents. 
Table 2.The Reality Use of Computers and Networks

\begin{tabular}{|c|c|c|c|c|}
\hline $\mathbf{N}$ & Statements & Question & Frequency & Percentage (\%) \\
\hline \multirow[t]{4}{*}{1} & \multirow{4}{*}{$\begin{array}{l}\text { Are a number of computers } \\
\text { that available in sections of } \\
\text { work adequate and } \\
\text { proportionate for the work } \\
\text { requirements? }\end{array}$} & Yes & 48 & 33.6 \\
\hline & & No & 78 & 54.5 \\
\hline & & Don't know & 17 & 11.9 \\
\hline & & Total & 143 & 100 \\
\hline \multirow[t]{4}{*}{2} & \multirow{4}{*}{$\begin{array}{l}\text { Does the quality of the } \\
\text { available devices sufficient } \\
\text { to achieve the work } \\
\text { requirements and needs? }\end{array}$} & Yes & 29 & 20.3 \\
\hline & & No & 99 & 69.2 \\
\hline & & Don't know & 15 & 10.5 \\
\hline & & Total & 143 & 100 \\
\hline \multirow[t]{4}{*}{3} & \multirow{4}{*}{$\begin{array}{l}\text { The current number of } \\
\text { ancillary equipment, is it } \\
\text { adequate to meet the work } \\
\text { requirements? }\end{array}$} & Yes & 49 & 34.3 \\
\hline & & No & 88 & 61.5 \\
\hline & & Don't know & 6 & 4.2 \\
\hline & & Total & 143 & 100 \\
\hline \multirow[t]{4}{*}{4} & \multirow{4}{*}{$\begin{array}{l}\text { Is the computer you are } \\
\text { using connected to the } \\
\text { domestic network? }\end{array}$} & Yes & 52 & 36.4 \\
\hline & & No & 90 & 62.9 \\
\hline & & Don't know & 1 & 0.7 \\
\hline & & Total & 143 & 100 \\
\hline \multirow[t]{3}{*}{5} & \multirow{3}{*}{$\begin{array}{l}\text { Is the computer you are } \\
\text { using connected to the } \\
\text { Internet? }\end{array}$} & Yes & 72 & 50.3 \\
\hline & & No & 71 & 49.7 \\
\hline & & Total & 143 & 100 \\
\hline
\end{tabular}

The analysis of the obtained results per-question in Table (2) was presented as follows:

1. As confirmed by approximately $54.5 \%$ of the respondents, the numbers of devices and computers currently available in the work departments are not sufficient to adequately achieve the work requirement. In contrast, $33.6 \%$ of the respondents stated that the numbers of available computers are adequate and proportionate for work requirements. Accordingly, the results indicated that a number of computers are not commensurate with the work requirements. Consequently, the given security institution may fail in facing of crises in various stages when it took place due to the lack of IT equipment.

2. Disagree with the idea of the devices quality is sufficient to match the work needs and requirements, while only $20 \%$ of the study population agrees with the designed question. Based on the obtained results, no doubt that the quality of the available computers in the SSI is inappropriate for accomplishing the work requirements, which raises a serious warning that the available IT equipment needs to be replaced by a modern one or fixed properly particularly in the time of crises and disasters.

3. As shown from the table, a high percentage of $61.5 \%$ (88 employees) disagreed with the idea that the current number of ancillary equipment's was adequate to meet the work requirements. This confirmed that the existing technology does not meet the purposes and aims especially when compared with modern technology available in the neighboring countries.

4. The results also showed a high percentage of 62.9\% (90 employees) disagreed with the idea that the used computers are connected to the computers on the domestic network, while $52 \%$ agree with the designed question. This clearly indicates that there was a weakness in the possibilities of the institution and needs to develop. 
5. Question number 5 was designed to figure out if the employees in the studied institutions use the internet for dictation and knowledge of previous crises, and how to control them so as to identify the weaknesses in the management and how to fix it. Results show that about $50.3 \%$ of the available computers in the SSI considered by the study are connected with internet network. A total of $72(50.3 \%)$ persons stated that the computers which they used are connected with internet network, while $71(49.7 \%)$ of them are not connected to the internet. The results indicated that there is sufficient access to the internet in the SSI which facilitates the access to information and knowledge of previous crises in the state or the undergoing ones in the neighboring countries. On the other hand, the accessibility to the internet under the lack of security network programs or lack of awareness of the senior leadership of the importance of networking could be a source of crises itself in the case of electronic attacks.

\subsection{The Reality Use of Software and Databases}

Table 3. The Reality Usage of Software and Databases

\begin{tabular}{|c|c|c|c|c|}
\hline $\mathrm{N}$ & Statements & Question & Frequency & Percentage (\%) \\
\hline \multirow[t]{4}{*}{1} & \multirow{4}{*}{$\begin{array}{l}\text { Does the computer timely } \\
\text { help to facilitate the } \\
\text { retrieval of information? }\end{array}$} & Yes & 98 & 68.5 \\
\hline & & No & 40 & 28 \\
\hline & & $\begin{array}{l}\text { Don't } \\
\text { know }\end{array}$ & 5 & 3.5 \\
\hline & & Total & 143 & 100 \\
\hline \multirow[t]{4}{*}{2} & \multirow{4}{*}{$\begin{array}{l}\text { Are the computers linked } \\
\text { to the active database for } \\
\text { easier referral in decision- } \\
\text { making processes? }\end{array}$} & Yes & 54 & 37.8 \\
\hline & & No & 86 & 60.1 \\
\hline & & $\begin{array}{l}\text { Don't } \\
\text { know }\end{array}$ & 3 & 2.1 \\
\hline & & Total & 143 & 100 \\
\hline \multirow[t]{4}{*}{3} & \multirow{4}{*}{$\begin{array}{l}\text { Does the computer } \\
\text { improve your ability to } \\
\text { solve challenges faced in } \\
\text { your job? }\end{array}$} & Yes & 110 & 76.9 \\
\hline & & No & 31 & 21.7 \\
\hline & & $\begin{array}{l}\text { Don't } \\
\text { know }\end{array}$ & 2 & 1.4 \\
\hline & & Total & 143 & 100 \\
\hline \multirow[t]{4}{*}{4} & \multirow{4}{*}{$\begin{array}{l}\text { Do the computers have } \\
\text { special programs and } \\
\text { software installed that can } \\
\text { be used in crisis } \\
\text { management? }\end{array}$} & Yes & 34 & 23.8 \\
\hline & & No & 93 & 65 \\
\hline & & $\begin{array}{l}\text { Don't } \\
\text { know }\end{array}$ & 16 & 11.2 \\
\hline & & Total & 143 & 100 \\
\hline \multirow[t]{4}{*}{5} & \multirow{4}{*}{$\begin{array}{l}\text { Do the computers help to } \\
\text { speed up the rate of work } \\
\text { and dealing with } \\
\text { emergencies? }\end{array}$} & Yes & 72 & 50.3 \\
\hline & & No & 57 & 39.9 \\
\hline & & $\begin{array}{l}\text { Don't } \\
\text { know }\end{array}$ & 14 & 9.8 \\
\hline & & Total & 143 & 100 \\
\hline \multirow[t]{4}{*}{6} & \multirow{4}{*}{$\begin{array}{l}\text { Is there a lack of the role } \\
\text { that computers play when } \\
\text { it comes to development of } \\
\text { alternatives to resolve the } \\
\text { emerged crisis? }\end{array}$} & Yes & 75 & 52.4 \\
\hline & & No & 38 & 26.6 \\
\hline & & $\begin{array}{l}\text { Don't } \\
\text { know }\end{array}$ & 30 & 21 \\
\hline & & Total & 143 & 100 \\
\hline \multirow[t]{2}{*}{7} & \multirow{2}{*}{$\begin{array}{l}\text { Have the computers } \\
\text { contributed to the selection }\end{array}$} & Yes & 62 & 43 \\
\hline & & No & 70 & 49 \\
\hline
\end{tabular}




\begin{tabular}{|c|c|c|c|c|}
\hline \multirow{6}{*}{8} & \multirow[t]{2}{*}{ of the prompt alternatives? } & $\begin{array}{l}\text { Don't } \\
\text { know }\end{array}$ & 11 & 7.7 \\
\hline & & Total & 143 & 100 \\
\hline & \multirow{4}{*}{$\begin{array}{l}\text { Are the computers } \\
\text { programmed to backup } \\
\text { and to save data and } \\
\text { software in the event of a } \\
\text { technical fault? }\end{array}$} & Yes & 81 & 56.6 \\
\hline & & No & 48 & 33.6 \\
\hline & & $\begin{array}{l}\text { Don't } \\
\text { know }\end{array}$ & 14 & 9.8 \\
\hline & & Total & 143 & 100 \\
\hline
\end{tabular}

The discussion of the results obtained per-question and tabulated in Table (3) is presented as follows:

1. Based on the results obtained from question number 1 , a high percentage of employees $(68.5 \%)$ agree with the idea that the computer timely help to facilitate the retrieval of information, while about $28 \%$ of them disagree. This confirms one of the most important characteristics of computer features, which is represented by the information retrieval capacity on demand. On the other hand, there is a remarkable number of the study population (3.5\%) they do not have any opinion about the designed idea. This could be attributed to the fact that the security establishment to ensure its ranks of people with limited education because there is no any opportunity for them in education previously for many reasons.

2. Also, a high percentage $(60.1 \%)$ of the employees confirmed that the computers are not linked to the active database for easier referral in decision-making processes. The result could be attributed to that the employees did not use the computers in professional ways. Besides, about $37.8 \%$ of the employees agree with the idea that it is very necessary to have a database serving the operation room. As a result, help in decision-making and speed up in implementing the task of crisis process.

3. As confirmed by a high percentage $(76.9 \%)$ of the employees, the computer improves ability to solve the challenges faced by the employee during his job. It indicates that the importance of computers in solving complex problems, even though it is not available as required.

4. The Table shows that about $65 \%$ of the employees agree that there no special programs or software can be used in crisis management. And, $23.8 \%$ of them confirmed that there are limited special applications installed but not efficient. The results indicated that the weakness of these programs or lack of experts, so large number of employees does not trust them [12] Moreover, there are about 11.2\% employees did not know, this attributed to their low experience.

5. According to the question number 5, a total percentage of $50.3 \%$ employees agree with the opinion that computers help to speed up the rate of work in dealing with emergencies. This result confirms the significance of capacity, speed, and technical precision feature. Meanwhile, the percentage of $39.9 \%$ employees disagrees with the question; they do not trust the technology. Therefore, they rely on alternative methods in dealing with crises. A percentage of $9.8 \%$ employees did not have any opinion.

6 . Based on the question number 6 , about $52.4 \%$ of the studied employees agreed that there is a lack of the role played by computers when it comes to the development of alternatives in response to resolving a crisis. Meanwhile, there is a relatively low percentage $(26.6 \%)$ of employees do not agree with the question, although this results considered negative. It reflects the high acceptance of the employees to use IT such as computers that could play in the crises early warning, monitoring and management. This awareness of the employees may be gained by obtaining higher scientific degrees which make them able to understand the importance and the vital role of the computer in the development of alternatives to resolve the crisis. Moreover, there are a remarkable percentage of the employees (21. \%) do not have any opinion about the designed idea. Such kind of response could be attributed that employees did not have high scientific 
degrees which make them able to determine the importance of computer in the development of alternatives resolve the crisis.

7. The question number 7 was designed to investigate the contribution of available computers to select the prompt alternatives to resolve the crisis emerged. The results showed that a number of $70(49 \%)$ employees disagree with the idea stated that the computers have contributed to provide a selection of prompt alternatives, while about $43 \%$ of the study population agree. The high percentage of the population who stated that the computers have not contributed to providing alternatives they represent those employees constituted the owners of competence in the technology area, and able to take benefits from their computers. Moreover, there is a low percentage of employees $(7.7 \%)$ they did not have any opinion which due to lack enough knowledge about the existing technology in their hands and how to exploit it

8. The study question number 8 to figure out the computers programmed to backup and to save data, and the software in the event of a technical fault in the SSI. Recently, Organizations have become convinced that, they should make contingency plans for coping with IT and information security incidents, and ensure that backup copies are stored in a safe location $[15-16,13]$. The results obtained based on the responses of the study population, which indicate that there is a relatively high percentage of $(56.6 \%)$ agree with applying of this system. This shows that there is already saved copies of data outside the workplace, due to fear of damage to the subsequent destruction of the place, whether it was the result of an earthquake, fire, virus, or inadvertently deleted programs. Meanwhile, there is about $33.6 \%$ of the employees disagree, whereas a percentage of $9.8 \%$ of the employees do not have an idea due to their ignorant about this subject.

\subsection{Efficiency and Obstacles and Solutions Used Of ICT}

In this part of the study, a questionnaire was designed three major items, in which the first item (Efficiency) addressing the issue of efficiency of IT in the crisis management by analyzing the response of the study population upon thirteen designed questions. The second item (Obstacles) consists of fourteen questions investigating the obstacles that hinder the efficient use of IT in facing the crises. The fourteen questions are generally associated to response to the hypothesis: there are obstacles hinder the efficient use of IT in facing the crises. Finally, the third item (Solutions) through fifteen designed questions, proposes some solutions to overcome obstacles that hinder the use of IT at the time of the crisis. The fifteen questions are generally associated with collection responses from the study population about suggested solutions, by the author, to overcome the obstacles that hinder the efficient use of IT in facing the crises.

The tendency was obtained by applying the following scale: low agreement of the respondents with the designed questions if obtained value (based on the Five-point rating scales) is between $1-2.49$; medium agreement if the value between $2.50-3.49$; high agreement if the value is between $3.50-5$.

Table 4. Efficiency, Obstacles and Solutions on Usage of ICT

\begin{tabular}{|c|c|c|c|c|c|c|c|c|c|}
\hline Institutions & No. & Mean & SD & $\mathrm{SE}$ & $\begin{array}{l}\text { Con } \\
\text { Inte } \\
\end{array}$ & $\begin{array}{l}\% \\
\text { dence } \\
\text { al for } \\
\text { an }\end{array}$ & Rank & $\begin{array}{c}\text { F- } \\
\text { value }\end{array}$ & Sig \\
\hline \multicolumn{10}{|c|}{ Efficiency } \\
\hline Police & 35 & 3.05 & .98 & .16 & 2.71 & 3.39 & Medium & \multirow{2}{*}{3.67} & \multirow{2}{*}{0.014} \\
\hline Police & 31 & 3.19 & .76 & .13 & 2.91 & 3.47 & Medium & & \\
\hline
\end{tabular}




\begin{tabular}{|c|c|c|c|c|c|c|c|c|c|}
\hline Hospitals & & & & & & & & & \\
\hline $\begin{array}{l}\text { Civil } \\
\text { Defense }\end{array}$ & 39 & 3.11 & .74 & .11 & 2.87 & 3.35 & Medium & & \\
\hline $\begin{array}{l}\text { Command } \\
\text { and Control }\end{array}$ & 38 & 3.60 & .67 & .10 & 3.38 & 3.83 & Medium & & \\
\hline Total & 143 & 3.24 & .82 & .06 & 3.11 & 3.38 & Medium & & \\
\hline & & & & Obs & icles & & & & \\
\hline Police & 35 & 3.67 & .72 & .12 & 3.42 & 3.91 & High & \multirow{5}{*}{.324} & \multirow{5}{*}{.808} \\
\hline $\begin{array}{l}\text { Police } \\
\text { Hospitals }\end{array}$ & 31 & 3.51 & .68 & .12 & 3.26 & 3.76 & High & & \\
\hline $\begin{array}{l}\text { Civil } \\
\text { Defense }\end{array}$ & 39 & 3.62 & .61 & .09 & 3.42 & 3.82 & High & & \\
\hline $\begin{array}{l}\text { Command } \\
\text { and Control }\end{array}$ & 38 & 3.57 & .63 & .10 & 3.36 & 3.78 & High & & \\
\hline Total & 143 & 3.59 & .65 & .05 & 3.49 & 3.70 & High & & \\
\hline \multicolumn{10}{|c|}{ Solutions } \\
\hline Police & 35 & 3.95 & .34 & .05 & 3.83 & 4.07 & High & \multirow{5}{*}{3.15} & \multirow{5}{*}{.027} \\
\hline $\begin{array}{l}\text { Police } \\
\text { Hospital }\end{array}$ & 31 & 3.81 & .23 & .04 & 3.73 & 3.90 & High & & \\
\hline $\begin{array}{l}\text { Civil } \\
\text { Defense }\end{array}$ & 39 & 3.88 & .68 & .10 & 3.66 & 4.10 & High & & \\
\hline $\begin{array}{l}\text { Command } \\
\text { and Control }\end{array}$ & 38 & 4.12 & .34 & .05 & 4.01 & 4.23 & High & & \\
\hline Total & 143 & 3.95 & .45 & .03 & 3.87 & 4.02 & High & & \\
\hline
\end{tabular}

$* p \leq 0.05$

\subsection{Efficiency of ICT in Crisis Management}

To analyze the relationship between perceived effectiveness of ICT and crisis management by employees in operating rooms of SSI (i.e., would we evaluate the ICT efficiency of the crisis'), the institutions were divided into four sectors based on the number of responses in each group as presented in Table 4. (I.e. on a scale of 1-5, with 1 $=$ strongly disagree and $5=$ strongly agree, for level of agreement with the statement: it had a solution to obstacles) A one-way between subjects ANOVA was conducted to find group differences, and there was a significant relationship between perceived effectiveness of ICT and crisis management at the $\mathrm{p}<.05$ level $[\mathrm{F}=3.67, \mathrm{p}=.014]$. Post hoc comparisons using the LSD test indicated that the mean police: $(n=35, M=3.05$, SD $=.98)$, Police Hospitals: $(\mathrm{n}=31, \mathrm{M}=3.19, \mathrm{SD}=.76)$, Civil Defense: $(\mathrm{n}=39, \mathrm{M}=3.11$, $\mathrm{SD}=.74)$, Command and Control $(\mathrm{n}=38, \mathrm{M}=3.60, \mathrm{SD}=.67)$ was significantly different in other institutions. 


\subsection{Major Factors that Hinder Effective Use of IT in Confronting Crises}

A one-way between subjects ANOVA was performed on the factors that hinder the use of ICT (i.e., 'On a scale of $1-5$, with 1 being strong disagree and 5 being very agree, how would you rate the hindering of the use) in which institutions were Police ( $\mathrm{n}=35, \mathrm{M}=$ 3.67, $\mathrm{SD}=.72)$, Police Hospitals $(\mathrm{n}=31, \mathrm{M}=3.51, \mathrm{SD}=.68)$, Civil defense $(\mathrm{n}=39, \mathrm{M}=$ $3.62, \mathrm{SD}=.61)$, Command and Control $(\mathrm{n}=38, \mathrm{M}=3.57$, $\mathrm{SD}=.63)$. No significant relationship was found $(\mathrm{F}=.324, \mathrm{p}=.808)$.

\subsection{Solutions that Proposed to Avoid Obstacles}

The relationship between solutions that proposed to avoid obstacles to the use of IT and crisis management in the operating room of SSI was tested using a one-way ANOVA (i.e., On a scale of $1-5$, with 1 being strongly disagree and 5 being strongly agree, for level of agreement with the statement: it had a solution to obstacles). There was a significant relationship between solutions and crisis management in terms of institutions at the $\mathrm{p}<.05$ level $[\mathrm{F}=3.15, \mathrm{p}=.027]$. Post hoc comparisons using the LSD test indicated that the mean for police $(\mathrm{M}=3.95, \mathrm{SD}=.35)$, did not significantly different from police hospitals $(\mathrm{M}=3.81, \mathrm{SD}=, 23)$, civil defense $(\mathrm{M}=3.88, \mathrm{SD}=.681)$ and command and control $(\mathrm{M}=4.12, \mathrm{SD}=.34)$ was significantly different. One regression was conducted to test hypotheses, for all three dependent variables (efficiency, obstacles, solutions), a block that included institutions.

\subsection{Hypotheses Tests}

As shown in Table 5 there is a significant relationship between the level of efficiency and IT contribution in crisis management in the operating room of SSI. The research findings indicated that the efficiency $(\mathrm{F}=3.67, \mathrm{P}=.014<0.05)$ is found to have a direct relationship with efficiency, in reject of the hypothesis $\mathrm{H} 1$.

There is no significant relationship between the perceived factors that hinder the use of IT and crisis management in operating room of SSI. The research findings indicated that perceived the factors that hinder the use of IT $(\mathrm{F}=.324, \mathrm{p}=.808>0.05)$ is found to have a direct relationship with obstacles, in support of the hypothesis $\mathrm{H} 2$.

There is a significant relationship between the solutions that proposed to avoid obstacles for the use of IT and crisis management in the operating room of SSI. The research findings in this study indicate that solutions $(\mathrm{F}=3.15, \mathrm{p}=0.027<0.05)$ is found to have a direct relationship with crisis management,

Table 5. The Summary of Findings

\begin{tabular}{|l|l|l|}
\hline No & \multicolumn{1}{|c|}{ The Research Hypothesis } & \multicolumn{1}{|c|}{$\begin{array}{c}\text { The } \\
\text { results }\end{array}$} \\
\hline H1 & $\begin{array}{l}\text { No relationship (effect) is statistically significant at (0.05) level } \\
\text { between the efficiency of IT and variable of SSI. }\end{array}$ & Rejected \\
\hline H2 & $\begin{array}{l}\text { No relationship (effect) is statistically significant at (0.05) level } \\
\text { between the factors that hinder the use of IT and variable of SSI. }\end{array}$ & Supported \\
\hline H3 & $\begin{array}{l}\text { No relationship (effect) are statistically significant at the (0.05) level } \\
\text { between the solutions that proposed to avoid obstacles to the use of ICT } \\
\text { and variable of SSI. }\end{array}$ & Supported \\
\hline
\end{tabular}




\section{Discussions}

The results of this study diagnosis the reality of the infrastructure and provide suggestions for future crisis communication and coordination work, which is applicable to SSI to detect the gap in crisis management literature. In particular, this is the first study, which is emphasizing on, the role of ICT in SSI for facing the crises in the security sector in Yemen. This study had investigated how security authorities can effectively prepare to overcome with these rare events. On the basis of previous ICT literature, we examine the weaknesses and strengths of traditional approaches to crisis response and crisis preparation. ICT allows the Disaster Management Network interactive creation, facilitates communication at the same time to focus on the same problem.

\subsection{The Reality of the Use of Computers and Networks}

Many researchers show that larger institutions had a higher level of infrastructure than smaller institutions in most countries [17-19]. ICT has become critical infrastructure, it allows the Disaster Management Network interactive creation, facilitates communication at the same time to focus on the same problem [20-21]. In this study, the results of the questionnaire survey from IT designed indicate that there were not positive answers to the availability of computers and networking required during the crisis management. It means assessing to a percentage of available technology in crisis management were low, ranging from $(20.3 \%-50.3 \%)$ when asked to evaluate from operations room employees in the event of crises and disasters.

Therefore, there is an urgent need to modernize and develop the technology infrastructure in the SSI to link internal and external local networks because it will be provided an ease to transfer information in the real time. . Furthermore, the exchange of experiences between the sections and departments of the SSI, linking World Wide Web to keep pace with the knowledge and experiences of developed countries. Moreover, the results pointed out the importance of providing various alerts devices, tools and equipment's (e.g., cars, cameras, ambulance, surveillance devices) and the financial support; as well as human resources training for the staff to follow-up technical development, raising up the qualifications of the staffs leading to an effective and positive influence on the crisis management.

\subsection{The Reality of the Use of Software and Databases}

Although scientists and researchers fairly agree [22-23, 17] that there is a positive relationship between preparations of the crisis and reduce the negative effects of the crisis, this indicates that more scientific work needs to be done for the usage of IT and planning to respond the crisis and mitigate damages. In addition, the obtained results shed a light on the necessity of taking to attention to special programs for crisis management and set up a database for the purpose of archiving and retrieval in time and work the backup copies for saving from damage in a safe location. Results from this study revealed that there are a respectable awareness and acceptance among operation room employees about the importance of the IT applications, which can play an important role in the crises early warning, monitoring, and management. Therefore, to reach the ideal decision support systems should develop and improve the information systems that collect, analyze and disseminate necessary information to the decision-maker of crisis management, [24].

\subsection{Efficiency of ICT in Crisis Management}

It can be observed that the arithmetic means for all Five-point rating scales upon response to the thirteen questions that included of efficiency is estimated by 3.248 and found to be statistically significant at 0.05 . Whereas most research states that the bigger the organization the higher preparedness [18-19], it was encouraging to study in the field 
of security sector to identify the significant relationship between SSI and efficiency of ICT in crisis management. This arithmetic mean was located within the range $2.50-3.49$, which indicates that there was a medium agreement among the respondents with the designed idea of this item. In other words, the efficiency of IT has a significant impact on crisis management. Furthermore, results pointed out that the availability of modern resources (e.g., cars, cameras, ambulance, surveillance devices) and follow-up technical development and training for the IT employees could positively affect in crisis management, through control and reduce its consequences. Further analysis has been conducted to assess the efficiency use of IT in each of SSI based on the responses of the study population upon the designed question in this item.

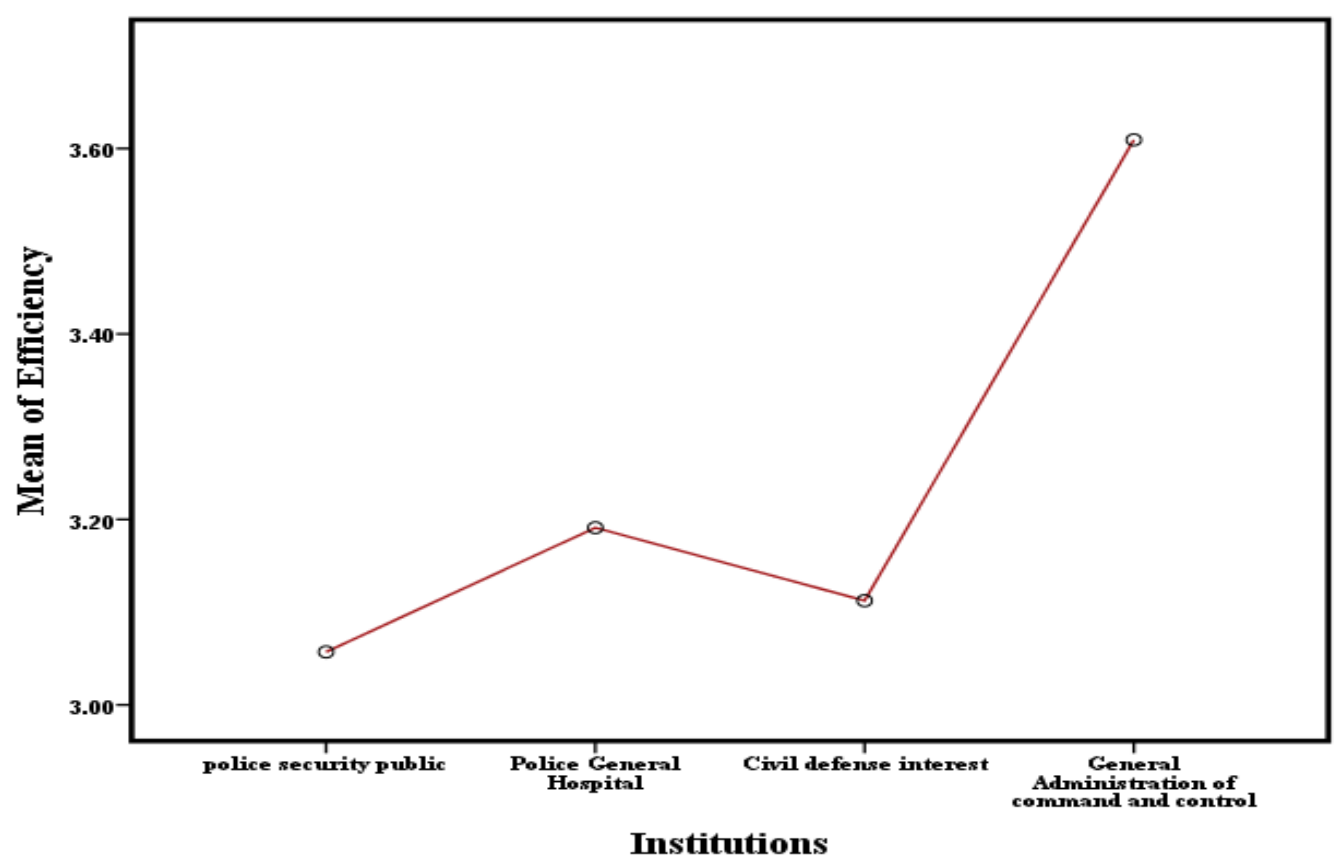

Figure 2. The Efficiency of ICT in Crisis Management

Figure 2 shows the level of the efficient use of IT in the aforementioned institutions. It can be observed that the highest level of IT efficiency use was recorded by the Command and Conflicts, while the lowest level was found in the Police. Attribute it to the greater interest of the leadership of the institution of command and control than other institutions because of the large dependence on the unity of command and control in crisis management. This raises another important concern for developing and improving the information systems and interest in the introduction of technology in other institutions because confronting of the crisis requires cooperation, integration, and coordination between all.

\subsection{Major Factors that Hinder Effective Use of ICT in Confronting Crises}

From the Table 4, the arithmetic mean for all Five-point rating scales upon response to the fourteen questions that included of obstacles were estimated by 3.59 and found to be not statistically significant The obtained value of the arithmetic mean is located within the range $3.50-5$, which indicated that there is high agreement of the respondents with the designed idea of this item. This confirmed that there are non-negligible obstacles hinder the efficient use of IT in facing the crises which may have a negative effect on crisis management in SSI. The high agreement of the respondents with the designed idea may indicate to inherent obstacles in SSI. Such as lack of necessary equipment and its supplies, the weakness in the use of specialized systems dealing with crises in the security sector. 
There is lack of technical workers in the SSI structures of specialists and also no support from senior management for the adoption of necessary strategies. Therefore, it is required from the senior management to find out the ways to update the technology and use specialized security systems in the workplace in order to keep up with development and increased professionalism.

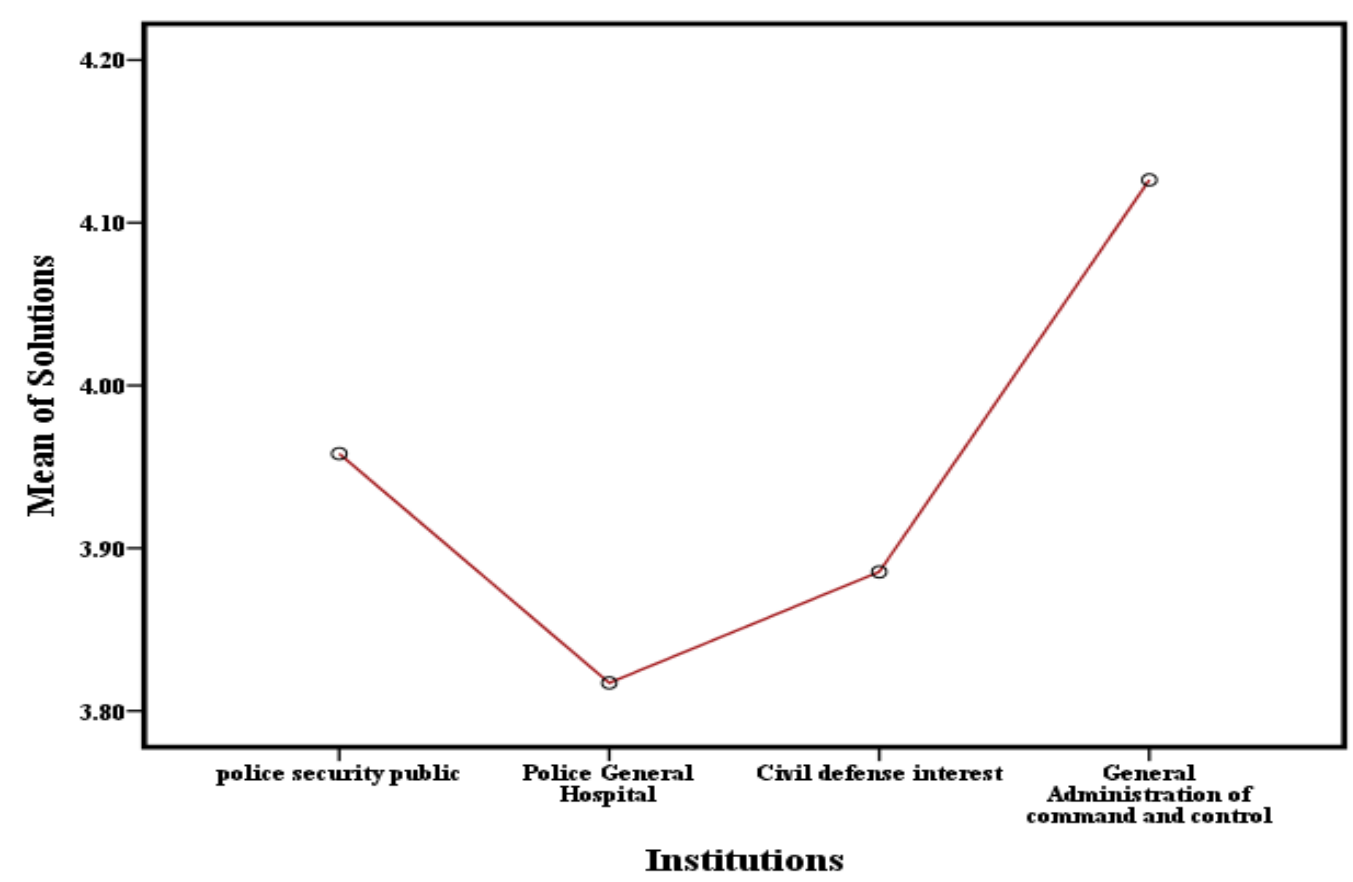

Figure 3. Major Factors that Hinder Effective Use of IT in Confronting Crises

Figure 3 shows the existence of the obstacles that hinder the efficient use of IT in facing the crises in each of SSI. It can be seen that the Police and Civil Defense facing the highest rate of IT use obstacles, while there are fewer obstacles facing the Police Hospitals and Command and Control to use the IT at the time of crisis efficiently. Comparing with the efficiency, it could be noticed that there is a negative correlation between the efficient use of IT and the obstacles in both of the institutions (Command and Control and (Police), i.e. the institution fewer obstacles has a higher efficiency in using the IT and vice versa.

\subsection{Solutions to Overcome Obstacles of Using the IT in Confronting Crises}

Based on the analyzed responses of the designed questions, it was found that the arithmetic mean of Five-point rating scales is 3.95 , which is statistically significant. The obtained value of the arithmetic means is located within the range $3.50-5$, which indicated that there is a high agreement of the respondents with the designed idea of this ITEM. The results indicated that the existence of efficient information system, integrated communications and well exploiting the existing technology, as well as the presence of administrative fully-trained staff, and senior management's awareness about the importance of IT in crisis management, will possibly lead to a significant positive impact on crisis management. Accordingly, the designed hypothesis (i.e. $\mathrm{H} 1$, and $\mathrm{H} 3$ ) of this research are rejected, while the obstacles were not statistically significant at 0.05 level of confidence, according to the variable of institutions (workplace) thus hypothesis (H2) was supported. These findings confirmed that the efficiency of IT has a significant effect on the crisis management in operation room of SSI. Furthermore, the efficiency and the effectiveness of the crisis management are affected negatively by the emerged problems and obstacles that hinder the efficient use of the IT. Moreover, the proposed solutions to 
avoid those obstacles could have positive effects on the use of IT as well as on crisis management.

\section{Conclusion \& Recommendations}

Based on the analysis conducted above for the purposes of this study, the following conclusions can be drawn.

- There is a lack of infrastructure for ICT in the SSI in the Yemen's Interior Ministry

- There is a significant weakness in the effective use of IT and communications, which include physical resources (e.g. cars, cameras, ambulance, surveillance devices etc) as well as human skills and are, not, developed enough. There is a shortage of human resources and in the crisis management team, in addition to low interest the senior management of IT in accordance with national policy.

- The available technology infrastructure is limited and has inadequate resources and human potentials and communication process inadequate at the time of crisis. Based on the results of the study we recommend the following measure to overcome the problems and obstacles that face the application of ICT.

1. Effective communication channels and easy to use the event of a crisis should be provided as well as the availability of advanced technology in the field of (equipment, information, communication).

2. It is necessary to activate a crisis management and the establishment a joint operations room.

\section{Acknowledgements}

The authors would like to thank Faculty of business administration Hohai University for help. In addition thank ministry of Higher Education and Scientific Research in Yemen for support.

\section{References}

[1] B, Arjen. "The new world of crises and crisis management: Implications for policymaking and research." Review of Policy research 26, no. 4 (2009), pp 367-377.

[2] H, Philip. Managing complexity in the public services. Routledge, (2015).

[3] D, Mendonça and H, Bouwman, 'Information and communications technology for crisis management: Defining an agenda for scientific research. In Infrastructure Systems and Services: Building Networks for a Brighter Future (INFRA), First International Conference on 2008 Nov 10 (2008) (pp. 1-4). IEEE.

[4] B, Charles. "OECD Risk Management." (2013). p 5.

[5] S. Seifallah and M. Goaied. "Financial development, ICT diffusion, and economic growth: Lessons from MENA region." Telecommunications Policy 37.4 (2013), pp 252-261.

[6] Y. Al-rabway, 'The reality of the e-government project in the Republic of Yemen' Sixth e-Government Conference"The new public administration and e-government."Dubai - UAE, December (2007), 12-9.P. 7. http://unpan1.un.org/intradoc/groups/public/documents/arado/unpan029800.pdf, Arabic.

[7] J.M. Sharp, "Yemen: Civil War and Regional Intervention." Congressional Research Service 2 (2015).

[8] International Crisis Group Yemen, is Peace Possible? Middle East Report, (2016), N 1679 February. And Neil Partrick "Saudi Arabia's Problematic Allies against the Houthis," Sada, February 12, (2016).

[9] N.M. M. Fuad, Tang Zhen, and M.S.A. Abdeldime "National Information and Communication Technology Policy in Yemen: The Response of Security Sector for Decision-Making." In Proceedings of the World Congress on Engineering and Computer Science, vol. 2. (2015).

[10] N. J. Maude and M-C. Therrien. "Resilience Factors Reconciled with Complexity: The Dynamics of Order and Disorder." Journal of Contingencies and Crisis Management (2016).

[11] P. Alain and K. Kraemer. "Survey research methodology in management information systems: an assessment." Journal of management information systems 10, no. 2 (1993), pp 75-105.

[12] M. M. Ghannam and A. al-Atrash, 'The role of information technology in crisis management to those working in the operations rooms of the Palestinian security forces in the Ministry of Interior', Master Thesis from Khalel university-College of Graduate Studies and Research(2010), Arabic.

[13] A.A. Jarghoun, 'The role of information technology in the coordination between the Palestinian security agencies', this study has provided an update to the requirements for obtaining a master's degree in Business Administration, Islamic University - Gaza (2013), Arabic. 
[14] W. S. Chow and O. H. Wai, "Determinants of the critical success factor of disaster recovery planning for information systems." Information Management \& Computer Security 17, no. 3 (2009), pp 248-275.

[15] T. Ozgur. "Is your back-up IT infrastructure in a safe location?" Information Systems Frontiers 10.3 (2008): 375-383.

[16] J. F. Hair, "Essentials of business research methods". ME Sharpe, (2015).

[17] A. E. Johnson, M. Graham, and S. Park, "Planning Makes (Closer to) Perfect: Exploring United States' Local Government Officials' Evaluations of Crisis Management." Journal of Contingencies and Crisis Management 24.2 (2016), pp 73-81.

[18] J. W. Helle, K. Aggerholm, and F. Frandsen, "Entering new territory: A study of internal crisis management and crisis communication in organizations." Public Relations Review 38, no. 2 (2012), pp 270-279.

[19] Guth, David W. "Organizational crisis experience and public relations roles." Public Relations Review 21.2 (1995), pp123-136.

[20] L. K.Comfort, R. W. Theresa and E. N. James "Designing and emergency information system: the Pittsburgh experience." (1989).

[21] R. M. C.Bruno and A. Passarella. "Opportunistic networking overlays for ICT services in crisis management." In Proceedings of International Conference on Information Systems for Crisis Response and Management ISCRAM. (2008).

[22] Burnett, John J. "A strategic approach to managing crises." Public relations review 24, no. 4 (1999), 475-488.

[23] Kash, Toby J., and John R. Darling. "Crisis management: prevention, diagnosis and intervention." Leadership \& Organization Development Journal 19, no. 4 (1998), pp 179-186.

[24] O. E. N. Otieno, G.N.S.Anna and Fang Chen. "Concept for Intelligent Integrated System for Crisis Management." In Proceedings of the 7th International ISCRAM Conference-Seattle, vol. 1. (2010).

\section{Authors}
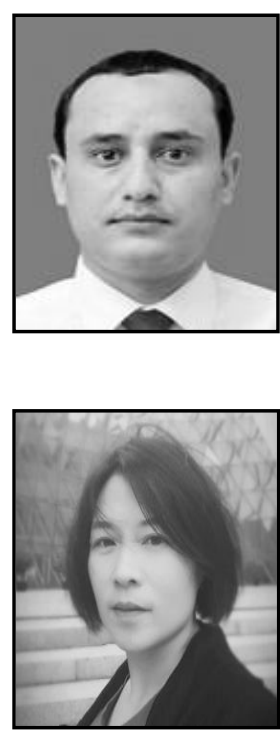

Fuad Mohsen Mohammed Nasr, is A PhD Student At Hohai University In China. He Will Receive His PhD Degree From Faculty Of Business School. He Holds A Master In International Business From Southeast University, and Holds B. Sc In Accounting And Finance From Sana'a University. Besides, His Research And Publications Focus On Topics Such As Crisis Management, Management Information Systems (MIS), Technology Management, And Information Systems.

Tang Zheng, is the voice present of Business School of Hohai University China. She has been working in Hohai University since 2004. She was a visiting scholar in Lehigh University and University of Calgary. Her research interest focuses on strategic management and transnational operation technique strategy and innovation management, and entrepreneurship and leadership. She has published books like "Strategic Management", "History of Management Thoughts" and so on. 